NBER WORKING PAPER SERIES

\title{
MANAGED CARE, DRUG BENEFITS AND MORTALITY: AN ANALYSIS OF THE ELDERLY
}

\author{
Gautam Gowrisankaran \\ Robert J. Town \\ Working Paper 10204 \\ http://www.nber.org/papers/w10204
}

\author{
NATIONAL BUREAU OF ECONOMIC RESEARCH \\ 1050 Massachusetts Avenue \\ Cambridge, MA 02138 \\ January 2004
}

We thank Victor Aguirregabiria, Joe Altonji, Bryan Dowd, Randy Ellis, Michael Keane, Joe Newhouse and seminar participants at Boston University, Centers for Medicare and Medicaid Services, University of Minnesota and Yale University for helpful comments. The views expressed herein are those of the authors and not necessarily those of the National Bureau of Economic Research.

(O)2003 by Gautam Gowrisankaran and Robert J. Town. All rights reserved. Short sections of text, not to exceed two paragraphs, may be quoted without explicit permission provided that full credit, including $\odot$ notice, is given to the source. 
Managaed Care, Drug Benefits and Mortality: An Analysis of the Elderly

Gautam Gowrisankaran and Robert J. Town

NBER Working Paper No. 10204

January 2004, Revised July 2006

JEL No. I11, I12, I18, C33

\begin{abstract}
$\underline{\text { ABSTRACT }}$
We seek to investigate whether managed health care can affect mortality, and if so, through which mechanisms. We estimate the impact of Medicare+Choice $(\mathrm{M}+\mathrm{C})$, Medicare's managed care program, on elderly mortality, using a county-level panel from 1993 to 2000. We control for endogenous $\mathrm{M}+\mathrm{C}$ penetration rates with county fixed effects and instrumental variables. We construct instruments using the identification created by the fact that $\mathrm{M}+\mathrm{C}$ payment rates are based on 3 - to 8 -year lagged fee-for-service (FFS) costs in the county. We find that enrollment in managed care without prescription drug coverage significantly increases mortality while enrollment in managed care with drug coverage has no significant impact, both relative to FFS. The impact of managed care penetration on mortality from heart disease appears to follow a similar pattern. The estimates suggest that a 10-percentage point increase in $\mathrm{M}+\mathrm{C}$ non-drug coverage would cause 51,000 additional deaths among the aged population in 2000 .

Gautam Gowrisankaran

John M. Olin School of Business

Washington University in St. Louis

Campus Box 1133, Simon Hall 277

One Brookings Drive

St. Louis, MO 63130

and NBER

gautam_gowrisankaran@nber.org

Robert J. Town

Division of Health Services Research and Policy

School of Public Health

University of Minnesota

Minneapolis, MN 55455

rjtown@umn.edu
\end{abstract}




\section{Introduction}

In the United States, the 1990s saw a dramatic rise of a relatively new organizational mechanism for financing and organizing health care: managed care. By the end of the decade the vast majority of individuals with private health insurance were enrolled in some form of managed care (Glied, 2000). By using utilization management, writing high powered contracts with plan providers, and perhaps most importantly, exercising bargaining power over providers, managed care offers a potentially more efficient alternative to traditional indemnity health insurance. ${ }^{1}$ However, part of the reduction in costs from managed care may be due to a lower quality of care.

The potential efficiency gains from managed care have influenced government policy. Starting in 1982, the Medicare administration offered managed care plans to its enrollees as a way to reduce expenditures in this gigantic government program. By 2000, $15 \%$ or over 6 million Medicare enrollees opted for a private health maintenance organization (HMO) instead of traditional Medicare insurance. More recently, the government implemented the Medicare Prescription Drug, Improvement and Modernization Act (MMA) of 2003 with two intertwined legislative intents: moving Medicare further towards managed care and increasing access to drug coverage for Medicare enrollees through managed care plans. Drug coverage has become increasingly important because of the development of many useful drug therapies over the last 30 years (Lichtenberg, 2002a and 2002b). The MMA has been criticized on several dimensions, including by researchers who believe that it may result in lower quality care and cause plans to design benefits in order to exploit adverse selection (see McAdams and Schwartz, 2006).

The purpose of this study is to evaluate the impact of Medicare HMOs on the quality of

\footnotetext{
${ }^{1}$ For instance, Cutler, McClellan and Newhouse (2000) find that the main effect of managed care is to lower prices paid to providers.
} 
healthcare, using data from 1993 to 2000 . We define quality using what is generally considered the most important outcome measure, mortality, in our case mortality for the elderly. ${ }^{2}$ Medicare HMOs may offer benefits that exceed the basic Medicare package. Generally the most valued additional benefit is drug coverage and hence a related purpose of this study is to evaluate the impact of drug coverage, as provided by HMOs, on mortality. We specify a model of HMO entry, pricing and benefit decisions, and Medicare enrollee plan choices and health outcomes. We use the model to derive estimating equations and methods that are consistent with endogenous selection into HMOs and, in conjunction with the estimates, to provide evidence on the equilibrium provision of quality and the extent of adverse selection in this market and on the relative benefit to costs of the Medicare HMO program and Medicare drug coverage.

We hope that our study will inform the policy debate on the impact of Medicare HMOs and drug coverage on health outcomes, and through that, provide more general evidence on the impact of managed care on the quality of healthcare. The literature on the impact of Medicare HMOs on mortality has not reached any consistent conclusions, ${ }^{3}$ and neither has the overall literature on the effect managed care of penetration on health outcomes. ${ }^{4}$ A likely reason for the inconsistent findings may be an endogeneity problem, where people are likely to select into HMOs and drug coverage on the basis of their health status, and health status is not perfectly observed. A number of other studies that assess the impact of managed care penetration on different outcomes have attempted to control for this endogeneity problem with a variety of

\footnotetext{
${ }^{2}$ There are many other measures of health outcomes including (but not limited to) morbidity, physical functioning status, psychosocial functioning and quality of life (Donabedian, 1985). We focus on mortality as it is unambiguously a measure of health outcomes, measurement error is modest and it is readily measured with available data.

${ }^{3}$ While Maciejewski et al. (2001) and Riley et al. $(1989,1991)$ find that Medicare HMO enrollees have a lower probability of death than other Medicare enrollees, other studies find no significant difference between the groups for breast cancer, prostate cancer, end-stage renal dialysis, and acute myocardial infarction (see Lee-Feldstein et al., 2000, Roetzheim et al., 2000, Potosky et al., 1999, Eggers et al., 2002, and Sada et al., 1998).

${ }^{4}$ A review by Miller and Luft (2002) reports that over the period 1997-2001, 9 studies find that HMOs lead to lower mortality, 12 find that HMOs lead to higher mortality, and 6 find no difference.
} 
methods. ${ }^{5}$

Our data provide us with a unique source of quasi-experimental variation that allows us to address the endogeneity problem in a manner that is consistent with our model. The quasiexperimental variation is based on peculiarities of the method by which the Medicare administration reimbursed HMOs for providing healthcare to its enrollees: until 1997, HMOs were reimbursed with a fixed payment rate based on the mean realized per-capita FFS expenditures in the county over a six year period, from 8 years prior to 3 years prior. ${ }^{6}$ Provided that unobserved shocks to health status in a county are sufficiently independent that there is no correlation between the shocks in a given year and three years prior, the payment rate can be used to construct instruments. The unobserved shocks are more likely to be independent if we include sufficient observed measures of health status. Our observed measures are extensive; they include a county fixed effect, the contemporaneous health status of younger people (as measured by mortality), detailed demographic data, and measures of supplemental health coverage (such as Medigap and Medicaid). We also provide evidence on the empirical validity of the independence assumption.

As an example of the forces that will identify our parameters, suppose County A in 1993 has a Medicare patient who undergoes a costly and rare procedure for a potentially fatal condition, such as a heart transplant or a heart assist implant. ${ }^{7}$ This will substantially boost County A's reimbursement rate in 1996 relative to 1995, which will cause plans to enter and offer drug benefits and lower prices (see Town and Liu, 2003). This will, in turn, increase

\footnotetext{
${ }^{5}$ Baker and Brown (1999) use instruments formed from the size distribution of firms (without fixed effects), Cutler, McClellan, Newhouse (2000) use fixed effects, and Dranove, Simon and White (2002) use fixed effects with long differences.

${ }^{6}$ As we detail below, the reimbursement scheme was different for the last three years of our sample, but the same basic idea for identification will apply.

${ }^{7}$ In 2002 Medicare paid for 484 heart transplants and 562 heart assist implants. The cost of these procedures to Medicare often exceeds $\$ 370,000$ and $\$ 240,000$, respectively. A good portion of health care costs consist of such costly and rare procedures.
} 
enrollment in HMOs that offer drug coverage, which may affect County A's mortality rate in 1996. If unobserved health shocks that cause mortality are not correlated between 1993 and 1996, this will provide an appropriate and useful source of identification of the impact of managed care and drug coverage on mortality.

The remainder of this paper is divided as follows. Section 2 provides a background on the institutional framework. Section 3 explains our model and inference. Section 4 details the data. Section 5 presents the results. Section 6 concludes.

\section{Institutional background}

We focus on the Medicare program for the aged, which served 35 million of the 41 million Medicare enrollees in 2003. This traditional fee-for-service (FFS) Medicare program consists of several parts. Part A covers hospital stays (with a small deductible) and catastrophic care. Part A enrollment is automatic. In addition, enrollees can (and mostly do) enroll in Part B for a premium (that was $\$ 43.80$ per month in 1998). Part B covers physician services with a $20 \%$ coinsurance; lab and diagnostic tests; outpatient services with a $20 \%$ co-payment; and mental health care with a 50\% co-payment. Medicare's Part A and B programs do not cover long-term care, prescription drugs, preventive care, dental care, or eye care.

In 1982, Congress passed the Tax Equity and Fiscal Responsibility Act (TEFRA) which directed the Health Care Financing Administration (HCFA), now called the Centers for Medicare and Medicaid Services (CMS), to contract with HMOs to provide a managed care option to Medicare enrollees. Under Medicare + Choice $(M+C)$ or Medicare Part $C$, the names for the program starting in 1997, an $\mathrm{HMO}$ can contract with Medicare to offer an $\mathrm{M}+\mathrm{C}$ plan for a given county and year. In counties with available $\mathrm{M}+\mathrm{C}$ plans, Medicare beneficiaries can enroll or disenroll in an $\mathrm{M}+\mathrm{C}$ plan on a monthly basis. Beneficiaries who disenroll in an $\mathrm{M}+\mathrm{C}$ plan are 
automatically enrolled into Medicare FFS Part A.

Each contracting HMO agrees to accept all Medicare enrollees residing in the county who enroll with it, and to provide and assume the risk for all Part A and B covered services to the individual, within a set provider network. ${ }^{8}$ The HMO is also allowed to provide extra benefits, most notably drug coverage, reduced copays for physician visits, dental benefits, and coverage for eyeglasses and durable medical equipment. In exchange for providing healthcare, the HMO receives a per-enrollee payment from CMS. In addition, the plan could charge a monthly premium to the enrollee. ${ }^{9}$ The offered premiums and benefits are subject to CMS approval. For instance, prior to the enactment of the Budget Balanced Act of 1997 (BBA) each Medicare HMO had to be an existing commercial HMO in the metropolitan area with a Medicare HMO enrollment capped at $50 \%$ of its total enrollment in the area.

Each year from 1982 until 1997, CMS set the per-enrollee HMO payment at 95\% of its projected Part A and B cost to treat a similar enrollee in the FFS program. The per-enrollee payment is the sum of a county/year-specific base payment and an increment based on age and gender, and Medicaid, institutional and end-stage renal disease statuses of the enrollee. Until 1997, the projected base cost was the mean Medicare FFS claims for that county, for the period from eight to three years prior.

In 1997, President Clinton signed the Balanced Budget Act (BBA). The BBA (and its subsequent modifications) altered Medicare's payment methodology. From 1998 onwards, the monthly base payment rate was set to the maximum of three figures: a blended input price (which mixes an adjusted national rate and an area-specific rate); a floor rate of $\$ 367$; and a

\footnotetext{
${ }^{8}$ More precisely, for a given $\mathrm{M}+\mathrm{C}$ contract, HMOs submit proposed service areas, which are clusters of counties in a given locale, to CMS for approval.

9 Premiums were constrained to be non-negative during our sample period, although CMS started permitting negative premiums after our sample period.
} 
minimum rate increase of $2 \%$ per year. Subsequent legislation in the Balanced Budget Refinement Act of 1999 (BBRA) increased the floor rate to $\$ 475$ (and $\$ 525$ for large urban counties) and added a 5\% increase in the payments to previously underserved markets, starting in 2000. Importantly, updates to the county payments remained unaffected by new Medicare FFS claims in the county, implying that base payment rate continued not to be based on claims data in the county within the previous three years. The post-BBA payment formula led to a substantial relative decrease in the payment rate for most counties.

The 2003 MMA significantly changed the payment formula to Medicare HMOs, renamed the HMO program Medicare Advantage (MA) and established prescription drug coverage known as Medicare Part D. Part D drug coverage involves a peculiarity known as a "donut hole" where enrollees are partly covered for the first $\$ 2,250$ of pharmaceutical expenditures in a year, but then must pay all of the additional expenses until their total out-of-pocket expenditures reaches $\$ 3,600$ at which point they are insured by catastrophic coverage.

Most Medicare FFS enrollees (92\%) also have supplemental insurance that offers additional benefits above Parts A and B. This supplemental insurance is either individually purchased, provided by the government (through Medicaid, Veterans Affairs, or State Pharmaceutical Assistance) or by an employer. Often this coverage provides prescription drug benefits. Davis et al. (1999) report that of the non-M+C Medicare beneficiaries in 1995, 13\% also had Medicaid (which provided drug coverage to $90 \%$ of this group), $35 \%$ had employer sponsored Medigap insurance ( $86 \%$ with drug coverage), 31\% purchased Medigap in the individual market ( $46 \%$ with drug coverage), $3 \%$ had other government sponsored coverage ( $80 \%$ with drug coverage) and $9 \%$ had a mixture of coverage ( $80 \%$ with drug coverage).

\section{Model and inference}


We develop a simple model of health plan entry, benefit design, consumer choice and mortality for the $\mathrm{M}+\mathrm{C}$ market. We do not structurally estimate the model but rather use it to guide the development of estimating equations and the identification strategy.

We consider a metropolitan area that is composed of counties $c=1, \ldots, \mathrm{C}$ and existing commercial HMOs $\mathrm{j}=1, \ldots, \mathrm{J}$. Each year, each commercial HMO simultaneously decides in which counties, if any, to offer $\mathrm{M}+\mathrm{C}$ plans. An $\mathrm{HMO}$ that offers an $\mathrm{M}+\mathrm{C}$ plan would provide and be at-risk for the healthcare of any Medicare enrollee who chooses to enroll with it. Following the entry decision, each HMO must simultaneously decide on price and benefit structures for each county in which it operates in the $\mathrm{M}+\mathrm{C}$ market. Let $\mathrm{p}_{\mathrm{jtc}}$ denote plan $\mathrm{j}$ 's price and $\mathrm{b}_{\mathrm{jtc}}$ its benefit design for time $t$ and county c. ${ }^{10}$ Prices are constrained to be non-negative. We focus on the binary benefit choice of drug coverage or not. Let $\tilde{d}_{\text {jtc }}$ and $\tilde{n}_{\text {jtc }}$ respectively denote dummy variables for managed care plan with and without drug coverage.

There exists a set of Medicare enrollees in each county, $i=1 \ldots$, I. Let $\theta_{\text {itc }}$ denote health status, where a higher value of $\theta_{\text {itc }}$ indicates a higher probability of dying during the year. Each month, each enrollee observes the prices and benefits for each offered plan, and then must make a discrete choice between one of the $\mathrm{M}+\mathrm{C}$ plans offered in her county and the outside option, which is traditional FFS Medicare. We can write utility for any offered plan as:

$$
\mathrm{u}_{\mathrm{ijtc}}=\mathrm{f}\left(\mathrm{p}_{\mathrm{jtc}}, \theta_{\mathrm{itc}}, \mathrm{b}_{\mathrm{jtc}}\right)+\varepsilon_{\mathrm{ijtc}},
$$

where $\mathrm{f}(\cdot)$ is some function and $\varepsilon_{\mathrm{jitc}}$ is an idiosyncratic unobservable. We normalize the outside

\footnotetext{
${ }^{10}$ Plans may offer multiple products with different service offerings, but we do not model this.
} 
option, FFS Medicare, to have utility $\mathrm{u}_{\mathrm{i} 0 \mathrm{tc}}=\varepsilon_{\mathrm{i} 0 \mathrm{tc}}$. Let $\mathrm{h}_{\mathrm{itc}} \in\{0, \ldots, \mathrm{J}\}$ denote the chosen health plan, which maximizes (1).

Our choice model may result in adverse selection by enrollees. For instance, an enrollee in poor health (i.e., with a high $\theta_{\text {itc }}$ ) may be likely to choose an HMO because she values the service offerings highly. Alternately, she may be unlikely to choose an HMO because she values access to a broad set of health care providers. One would expect enrollees in poor health to care more about drug coverage and hence be more likely to choose a plan with $\tilde{\mathrm{d}}_{\mathrm{jtc}}=1$ than with $\tilde{\mathrm{n}}_{\mathrm{jtc}}=1$, all else being equal.

The marginal cost to a plan for treating an enrollee depends on the enrollee's health status and the plan's benefits:

$$
\mathrm{mc}_{\mathrm{ijtc}}=\mathrm{g}\left(\theta_{\mathrm{itc}}, \mathrm{b}_{\mathrm{jtc}}\right)
$$

for some function $\mathrm{g}(\cdot)$. HMOs will likely compete by offering benefits which are both beneficial to enrollees and costly. ${ }^{11}$ Firms may endogenously choose benefits, price and entry or exit to attract patients with a favorable cost profile, generating a second source of adverse selection.

In addition to the marginal cost, HMOs face fixed costs for being in the $\mathrm{M}+\mathrm{C}$ market in any year. We also allow for dynamic and spatial fixed cost variation: HMOs that were not in the $\mathrm{M}+\mathrm{C}$ market in the previous year may incur a sunk cost of entry, HMOs that were in the market in the previous year and then exit may incur a sunk exit cost (potentially negative), and HMOs

\footnotetext{
${ }^{11}$ Town and Liu (2003) find that the provision of drug coverage by $\mathrm{M}+\mathrm{C}$ plans generates significant consumer welfare.
} 
that operate in more than one county may incur geographic spillover costs (generally negative).

Each year, the Medicare administration sets a county/year reimbursement rate $r_{t c}$. The gross benefit to the HMO is the reimbursement rate $r_{t c}$ times its number of enrollees. The reimbursement formula changed over time due to the BBA (and subsequent legislation), but never depended on FFS costs within the immediate three previous years or directly on the $\mathrm{M}+\mathrm{C}$ plan's cost history. Thus, we can express

$$
\mathrm{r}_{\mathrm{tc}}=\mathrm{R}_{\mathrm{t}}\left(\mathrm{h}_{\mathrm{if \tilde { \textrm {t } }}}, \mathrm{mc}_{\mathrm{i} 0 \tilde{\mathrm{t} \tilde{\mathrm{c}}}} \mid 1 \leq \mathrm{i} \leq \mathrm{I}, \tilde{\mathrm{t}} \leq \mathrm{t}-3,1 \leq \tilde{\mathrm{c}} \leq \mathrm{C}\right),
$$

for some formula $\mathrm{R}_{\mathrm{t}}(\cdot)$. Firms will have some information, not necessarily perfect, about future reimbursement rates.

Following the choice of plans, individuals will realize their illness state, and obtain medical treatment that will either result in a cure for their illness or in death. ${ }^{12}$ Let $\mathrm{m}_{\text {itc }}{ }^{*}$ denote a latent index for the likelihood of death (we explain below how $\mathrm{m}_{\text {itc }}^{*}$ translates into actual mortality). We let $\mathrm{m}_{\text {itc }}^{*}$ be a function of the individual's health status and health coverage:

$$
\mathrm{m}_{\mathrm{itc}}^{*}=\theta_{\mathrm{itc}}+\gamma_{\mathrm{d}} \tilde{\mathrm{d}}_{\mathrm{h}_{\mathrm{itc}} \mathrm{tc}}+\gamma_{\mathrm{n}} \tilde{\mathrm{n}}_{\mathrm{h}_{\mathrm{itc}} \mathrm{tc}}
$$

where $\gamma_{d}$ and $\gamma_{n}$, the impacts of managed care with and without drug coverage relative to

\footnotetext{
${ }^{12}$ Our model does not allow for dynamic treatment effects where an individual might survive but be more likely to die in a subsequent year based on the received treatment. We explored such specifications but the coefficients on lagged treatment were small and insignificant.
} 
remaining in the Medicare FFS sector, are the key parameters of interest. ${ }^{13}$

To estimate our model, we express an individual's health status as a deviation from the county/year mean, by writing

$$
\theta_{\mathrm{itc}}=\beta \mathrm{x}_{\mathrm{tc}}+\xi_{\mathrm{tc}}+\tilde{\theta}_{\mathrm{itc}}
$$

where $x_{t c}$ are county/year mean observed health status measures, $\beta$ is a coefficient vector, $\xi_{\mathrm{tc}}$ is a mean zero unobserved component of aggregate mean health status, and $\tilde{\theta}_{\text {itc }}$ is a mean zero individual deviation from the aggregate health status. In addition, we proxy for the plan type for each individual, $\tilde{\mathrm{d}}_{\mathrm{h}_{\mathrm{itc}} \text { tc }}$ and $\tilde{\mathrm{n}}_{\mathrm{h}_{\mathrm{itc}} \text { tc }}$, with the county/time population means of these variables, which we define as $d_{t c}$ and $n_{t c}$, respectively. ${ }^{14}$ The use of proxies implies that the unobserved component of mortality will include both $\tilde{\theta}_{\text {itc }}$ and the difference between the actual plan type and the population mean plan type. Let this combined unobservable be defined as $\mathrm{e}_{\mathrm{itc}} \equiv \tilde{\theta}_{\mathrm{itc}}+\gamma_{\mathrm{d}}\left(\tilde{\mathrm{d}}_{\mathrm{h}_{\mathrm{icc}} \mathrm{tc}}-\mathrm{d}_{\mathrm{tc}}\right)+\gamma_{\mathrm{n}}\left(\tilde{\mathrm{n}}_{\mathrm{h}_{\mathrm{ict}} \mathrm{tc}}-\mathrm{n}_{\mathrm{tc}}\right)$. We can then rewrite (4) as

$$
\mathrm{m}_{\mathrm{itc}}^{*}=\beta \mathrm{x}_{\mathrm{tc}}+\gamma_{\mathrm{d}} \mathrm{d}_{\mathrm{tc}}+\gamma_{\mathrm{n}} \mathrm{n}_{\mathrm{tc}}+\xi_{\mathrm{tc}}+\mathrm{e}_{\mathrm{itc}}
$$

We estimate (6) by aggregating from the individual level to the county/year level and using linear instrumental variables (IV). We estimate results from two different aggregation methods to obtain evidence on the robustness of our results to functional form.

\footnotetext{
${ }^{13}$ We do not allow service offerings besides drug coverage and managed care to affect mortality.

${ }^{14}$ Note that proxy error is different than measurement error in that proxy error will not result in biased coefficient estimates in a linear regression.
} 
For our first method, we let $\mathrm{m}_{\mathrm{itc}}^{*}$ to be the probability of death for person $\mathrm{i}$ and take the mean of (6) across individuals in the county. Let $\mathrm{m}_{\text {tc }}$ denotes the Medicare enrollee mortality rate, and let $v_{\mathrm{tc}} \equiv \xi_{\mathrm{tc}}+\sum_{\mathrm{i}=1}^{\mathrm{I}} \mathrm{e}_{\mathrm{itc}} / \mathrm{I}$. We then obtain:

$$
\mathrm{m}_{\mathrm{tc}}=\beta \mathrm{x}_{\mathrm{tc}}+\gamma_{\mathrm{d}} \mathrm{d}_{\mathrm{tc}}+\gamma_{\mathrm{n}} \mathrm{n}_{\mathrm{tc}}+\mathrm{v}_{\mathrm{tc}}
$$

For our second method, we let $\mathrm{m}_{\mathrm{itc}}^{*}$ be a latent illness index, with death occurring if and only if $\mathrm{m}_{\mathrm{itc}}^{*}>0$ and let $\mathrm{e}_{\mathrm{itc}}$ be distributed as a logit (i.e., as the difference between two Type 1 extreme value error terms). We further make the assumption that there are enough people within a county/year so that the sampling error in the Medicare mortality rate will be roughly zero. For consistency of notation, let $v_{\mathrm{tc}} \equiv \xi_{\mathrm{tc}}$ for this specification. Following Berry (1994), a transformation of the aggregate mortality rate can then be expressed as a linear function of the regressors:

$$
\log \left(\frac{m_{t c}}{1-m_{t c}}\right)=\beta x_{t c}+\gamma_{d} d_{t c}+\gamma_{n} n_{t c}+v_{t c} .
$$

Both (7) and (8) may suffer from endogeneity. From (1), enrollees may choose different service offerings plans on the basis of $\theta_{\text {itc }}$, and in particular $\xi_{\mathrm{tc}}$. This will imply that $v_{\mathrm{tc}}$ will be correlated with enrollees' choices of plan, $h_{i t c}$, and through that with $\mathrm{d}_{\text {tc }}$ and $\mathrm{n}_{\mathrm{tc}}$. We control for the endogeneity using an instrumental variables approach, where functions of the payment rate 
are used as instruments for $\mathrm{d}_{\mathrm{tc}}$ and $\mathrm{n}_{\mathrm{tc}}$. Our main identifying assumption is that the residual component of health status, $v_{t c}$, is independent across time, specifically that $v_{t c}$ is independent from any 3-year-old or older health shocks. The validity of this assumption depends on the quality of the aggregate health status variables $x_{t c}$, which are extensive, as detailed in the introduction.

The model and identifying assumption imply that functions of $r_{t c}$ are valid instruments for both $\mathrm{d}_{\mathrm{tc}}$ and $\mathrm{n}_{\mathrm{tc}}$ : functions of $\mathrm{r}_{\mathrm{tc}}$ will affect the set of available $\mathrm{M}+\mathrm{C}$ plans, benefit structure and premiums of the plans, and through that the share of consumers who choose drug and nondrug plans. In addition, $r_{t c}$, and hence any function of $r_{t c}$, is based only on variables 3 years old or older and will not be correlated with $v_{\mathrm{tc}}$. Moreover, the model implies that different functions of $r_{t c}$ are jointly valid instruments for $\mathrm{d}_{t c}$ and $\mathrm{n}_{\mathrm{tc}}$. The economic reason for this is that the entry and benefit decisions are non-linear functions of $r_{t c}$. Hence, $d_{t c}$ and $n_{t c}$ can each be expressed as a linear combination of multiple non-collinear functions of $r_{t c}$ plus a residual, where the functions can be indicators for $r_{t c}$ being in different quantiles, for instance. As these multiple functions can all be excluded from the treatment equation (7) or (8) but all enter separately into the underlying selection equations determining $d_{t c}$ and $n_{t c}$, they allow us to jointly identify the impacts of $\mathrm{d}_{\mathrm{tc}}$ and $\mathrm{n}_{\mathrm{tc}}$ on mortality.

We illustrate the joint identification with a numerical example. Consider a simple data generating process with many similar counties which differ only in two exogenous dimensions: $v_{\mathrm{tc}}$ and $\mathrm{r}_{\mathrm{tc}}$. We let $\theta_{\mathrm{itc}}=v_{\mathrm{tc}}$, let $v_{\mathrm{tc}}=-.150$ percent of the time and $v_{\mathrm{tc}}=.1$ the other 50 
percent, and let $r_{\mathrm{tc}}$ vary continuously with a distribution that is independent from $v_{\mathrm{tc}}$. We assume that each county contains one (monopolistic) HMO, plan 1, with no fixed or sunk costs or geographic spillovers. Each HMO knows $v_{\mathrm{tc}}$ and $r_{\mathrm{tc}}$ before deciding on entry. We assume also that there is no consumer selection based on $\theta_{\text {itc }}$, that the price elasticity of demand is high enough so that price is always zero and that the idiosyncratic enrollee choice unobservables $\varepsilon_{\mathrm{ijtc}}$ are distributed type I extreme value. The $f(\cdot)$ function from (1) will then be only a function of $\mathrm{b}_{1 \mathrm{tc}}$. We let $\mathrm{f}\left(\tilde{\mathrm{d}}_{1 \mathrm{tc}}\right)=1, \mathrm{f}\left(\tilde{\mathrm{n}}_{1 \mathrm{tc}}\right)=0, \mathrm{mc}_{\mathrm{iltc}}\left(v_{\mathrm{tc}}, \tilde{\mathrm{d}}_{1 \mathrm{tc}}\right)=1.1\left(\mathrm{v}_{\mathrm{tc}}+1\right)$, and $\mathrm{mc}_{\mathrm{iltc}}\left(\mathrm{v}_{\mathrm{tc}}, \tilde{\mathrm{n}}_{1 \mathrm{tc}}\right)=v_{\mathrm{tc}}+1$ so that drug coverage both increases costs and utility, with a cost complementarity between drug coverage and illness severity. It is not necessary for us to specify the mortality process.

By standard logit formulas, the HMO will capture $50 \%$ of the market share with a nondrug $\mathrm{M}+\mathrm{C}$ plan, and $73.1 \%$ with a drug $\mathrm{M}+\mathrm{C}$ plan. Per-capita profits will be $\pi\left(\tilde{\mathrm{n}}_{1 \mathrm{tc}}\right)=.5\left(\mathrm{r}_{\mathrm{jtc}}-\left(v_{\mathrm{tc}}+1\right)\right)$ and $\pi\left(\tilde{\mathrm{d}}_{1 \mathrm{tc}}\right)=.731\left(\mathrm{r}_{\mathrm{jtc}}-1.1\left(v_{\mathrm{tc}}+1\right)\right)$. Simple algebra then shows that when $v_{\mathrm{tc}}=-.1$, the firm will enter with no drug coverage for $.9 \leq \mathrm{r}_{\mathrm{jtc}} \leq 1.18$, with no entry below this range and drug entry above this range. When $v_{\mathrm{tc}}=.1$, the entry pattern is similar, but the comparable range for entry with no drug coverage is $1.1 \leq \mathrm{r}_{\mathrm{jtc}} \leq 1.45$. Thus, non-drug entry will occur with a mid-range $r_{t c}$ and drug entry with a high $r_{t c}$, with the exact range depending on $v_{t c}$.

Because of the correlation between $v_{t c}$ and both $d_{t c}$ and $n_{t c}$, OLS estimates of (7) with this data generating process would be inconsistent. However, we could consistently estimate (7) with instruments $\hat{\mathrm{d}}_{\mathrm{tc}}=\left\{\mathrm{r}_{\mathrm{jtc}}>1.3\right\}$ and $\hat{\mathrm{n}}_{\mathrm{tc}}=\left\{1 \leq \mathrm{r}_{\mathrm{jtc}} \leq 1.3\right\}$, where $\{\cdot\}$ denotes an indicator function, as these instruments will be non-collinear predictors of both $d_{t c}$ and $n_{t c}$. Adding in all 
the other features of the model (e.g., multiple firms, consumer adverse selection) will make the relation between the reimbursement rate and drug or non-drug entry more complicated, but the same fundamental identification will apply. While the example uses two instruments for simplicity of exposition, one could add to the predictive power of the instruments by generating four instruments of indicators based on the cutoffs $.9,1.1,1.18$ and 1.45. Moreover, the dynamic and geographic cost complementarities in our model imply that we can add further predictive power by using future and past payment rates and payment rates from nearby counties as instruments.

Our actual choice of instruments is complicated by the fact that costs vary significantly across counties, implying that a payment rate that is generous in one county is not generous in another. As county population is highly correlated with costs, we normalize the payment rate based on population, by regressing the payment rate on four measures of population (county population, health services area (HSA) population, MSA population and county elderly population). We define the residual from this regression to be the "normalized payment rate," $\hat{\mathrm{r}}_{\mathrm{tc}}$. We then create 10 instruments based on $\hat{\mathrm{r}}_{\mathrm{tc}}$ : the rate, its second, third and fourth powers, its $\log$ and the square of its $\log$, and 4 dummies indicating its quintile (with one excluded). We also create 3 instruments that indicate the mean, minimum and maximum normalized payment rates in the MSA, to capture the geographic cost complementarities noted above. To exploit the variation from sunk costs, we then include these same 13 instruments for the previous and subsequent year, ${ }^{15}$ for a total of 39 instruments. Because there is a potential tradeoff between asymptotic efficiency (which dictates more instruments) and small sample bias (which dictates

\footnotetext{
${ }^{15} \mathrm{We}$ let the instrument be zero for years that are not in the sample.
} 
less), ${ }^{16}$ we also examined results with smaller sets of instruments.

A potential statistical issue with using these instruments is that they are not strictly exogenous: though our model and assumptions imply that $\hat{r}_{\mathrm{tc}}$ is uncorrelated with $v_{\mathrm{tc}}$ they also imply that $\hat{r}_{t c}$ is correlated with $v_{t-3, c}$ and further lagged residuals. Since fixed effects IV estimates are equivalent to estimates from a mean-differenced instrumental variables specification, the residual can be expressed as $v_{\mathrm{tc}}-\frac{1}{\mathrm{~T}} \sum_{\hat{\mathrm{t}}=1}^{\mathrm{T}} \mathrm{v}_{\hat{\mathrm{tc}}}$. In a short panel, there may be a correlation between $\hat{r}_{\mathrm{tc}}$ and this residual due to the $\frac{1}{\mathrm{~T}} \sum_{\hat{\mathrm{t}}=1}^{\mathrm{T}} \mathrm{v}_{\hat{\mathrm{tc}}}$ component of the residual. With a sufficiently long panel, shocks to $v_{\hat{\mathfrak{t}}-3, \mathrm{c}}$ (for instance) will have little impact on $\frac{1}{\mathrm{~T}} \sum_{\hat{\mathfrak{t}}=1}^{\mathrm{T}} v_{\hat{\mathfrak{t}}}$. Thus, the consistency of IV estimates with this type of instrument depends on asymptotics in time.

With 8 years of data, the asymptotic approximation is likely to be close to valid. Nonetheless, we develop a forward mean differenced specification which provides consistent results without requiring a long panel. This specification transforms the estimating equation by subtracting the forward mean (from $\mathrm{t}-1$ to $\mathrm{T}$ ) for each variable instead of the overall mean, keeping the same untransformed instruments as in the base specification. Thus, the transformed residual is $v_{\mathrm{tc}}-\frac{1}{\mathrm{~T}-\mathrm{t}} \sum_{\hat{\mathrm{t}}=\mathrm{t}-1}^{\mathrm{T}} v_{\hat{\mathrm{tc}}} \cdot{ }^{17}$ The instrument $\hat{\mathrm{r}}_{\mathrm{tc}}$ will then not be correlated with the transformed residual since the residual does not include long-lagged terms such as $v_{t-3, c}$. The transformation does result in a serial correlation in the residuals and thus we cluster our reported standard errors at the county level.

\section{Data}

\footnotetext{
${ }^{16}$ Different authors suggest different points along this tradeoff. For instance, for a panel data with serial correlation, Arellano and Bond (1991) suggest using every available instrument while Keane and Runkle (1992) suggest a more limited set.

${ }^{17}$ For observations in year 1 , the difference goes back only to year 1.
} 
Our study period is $1993-2000$. We choose 1993 as the start of the sample as prior to this year enrollment in Medicare HMOs was very small. We create a county-level panel data set of mortality rates and other county-specific information. The data come from seven different sources, listed in Table 1, that we merge together.

First, the mortality data is constructed using the Multiple Cause of Death data from the National Vitality Statistics. These data contain abstracted death certificate information including the county of residence, age, sex, and diagnosed cause of death for all deaths in the U.S. To ensure confidentiality, the county is listed only for those individuals who reside in a county of over 100,000 in population. Thus, we limit our sample to counties above this population threshold. We use these data to construct mortality rates for different age groups and causes of death.

Second, we merge the mortality data with county level data from CMS on M+C plan enrollments, plan prescription drug benefits, total Medicare enrollment, and the $\mathrm{M}+\mathrm{C}$ constant dollar payment rate. We define the drug benefit using the base plan as reported by CMS. ${ }^{18}$ Our data do not provide the specific limitations of the drug coverage and other available benefit information is prone to substantial reporting error, and thus our measure of plan benefits is binary. This is a limitation, as it implies that we must lump different levels of drug coverage together.

Third, we use information from CMS on the number of Medicaid enrollees by state and age category (65 to 74,75 to 84 , and 85 and older). We proxy for the county-level Medicaid penetration rate with the state-level rate.

\footnotetext{
${ }^{18}$ This may lead to measurement error to the extent that HMOs offer multiple M+C plans in a county, some with drug coverage and some without. However, the 2000 Medicare Current Beneficiaries Survey reports that 17.8\% of all $\mathrm{M}+\mathrm{C}$ enrollees are enrolled in a plan without drug benefits. The corresponding figure in our data is $17.3 \%$, suggesting that any measurement error is small.
} 
We gather demographic information from two sources. We use data on county per-capita income, poverty rates, population by age and race, number of practicing physicians and number of hospitals from the Area Resource File. We use detailed demographic data from the Census' Population Estimates Program in order to provide a more complete account of the entire age distribution of the elderly by county. These data provide annual county level projections of the population in each year in each county by age and sex category. The age categories that we use are $64,65, \ldots, 84$, and 85 and older.

In some specifications, we use data from InterStudy on the county-level commercial managed care penetration rate and information on the state-level average Medigap premiums from the American Association of Retired Persons (AARP), one of the largest sellers of Medigap policies. By regulation, Medigap plan benefits fall into 10 different categories, labeled A-J. Three of these plans, H-J, offer drug coverage. We use the Plan H data as they were the most widely available data on Medicare FFS prices for drug coverage. These databases are our sixth and seventh data sources.

It is useful to characterize the $\mathrm{M}+\mathrm{C}$ drug coverage since it is central to this paper. The structure of the benefit varies across three dimensions: generic drug co-payments, branded drug co-payments and the total maximum drug expenditure covered by the plan. We have detailed information on the plan drug benefit structure only for 2000 .

In 2000 , approximately $80 \%$ of the $\mathrm{M}+\mathrm{C}$ plans offered drug coverage with a mean monthly premium of $\$ 34.85$. Of the plans offering drug coverage, the mean co-pay for generic prescription drugs is $\$ 7.80$ ( std. dev. $=\$ 2.93$; median $=\$ 7$ ), and the mean co-pay for branded prescription drugs is $\$ 16.16$ (std. dev. $=\$ 6.12$; median $=\$ 15$ ). $89 \%$ of these plans cap the total annual enrollee expenditures on drugs, with $37 \%$ setting the cap at less than $\$ 1,000$ per year, and 
another $37 \%$ setting caps of over $\$ 3,000$ per year.

It is also useful to compare the prescription drug benefits to those offered through Medigap. Plans H-J all require a 50\% coinsurance on prescription drugs with Plans $\mathrm{H}$ and I capping the annual prescription drug expenditure at $\$ 1,250$ and Plan J capping it at $\$ 3,000 .{ }^{19}$ The cost of enrolling in a Medigap policy varies across geography and insurers. For the AARP, the mean (unweighted) monthly premium across states for plans H-J for 65 to 69 year old is $\$ 153.90$, $\$ 156.57$, and $\$ 192.57$, respectively. Thus, $\mathrm{M}+\mathrm{C}$ plans with drug benefits are significantly less expensive to Medicare enrollees than Medigap plans and, in general, they offer more generous coverage.

Tables 2 summarizes the major variables used in the study. The average elderly mortality rate was $5.08 \%$ during the sample period, a figure that declines by .13 percentage point over the period, suggesting the need for time-specific controls. Cancer and heart disease make up the biggest components of mortality, together accounting for about $60 \%$ of the average mortality rate. Mortality rates are rapidly increasing in age, ranging from .54\% for age $50-59$ to $8.59 \%$ for people age 75 or older.

In 1993, the average $\mathrm{M}+\mathrm{C}$ penetration rate across counties was $3.3 \%$, a figure that increased to $15.8 \%$ by 2000 . Medicare $\mathrm{M}+\mathrm{C}$ payments were about $\$ 445$ per month (in constant 2000 dollars), also rising over time. Drug penetration rates were always higher than non-drug penetration rates. There is substantial variation in the payment rate across counties - the standard deviation is $18 \%$ of the mean in 1993. Not reported in the tables, there is also substantial variation in the payment rate within a given county across time, with a within-county

\footnotetext{
${ }^{19}$ Plans H and I differ in other small respects. Plan I covers Medicare Part B excess charges and at-home recovery expenses while Plan $\mathrm{H}$ does not. Plan J offers the same benefits as Plan I with the addition of covering Medicare Part B deductible and preventive care.
} 
standard deviation of $\$ 37 .{ }^{20}$ Many counties have no $\mathrm{M}+\mathrm{C}$ plans, or no plans with drug coverage. For instance, by the end of our sample period, $34.6 \%$ of counties in our sample have no $\mathrm{M}+\mathrm{C}$ plan with drug coverage.

Table 4 provides some evidence on the relation between the changes in the $\mathrm{M}+\mathrm{C}$ payment rate and the changes in $\mathrm{M}+\mathrm{C}$ enrollment and elderly mortality rates, over the period 1993 to 2000. This table is meant to give an indication of the forces that will identify the estimates, as the fixed effects IV estimator with one (endogenous) regressor would be the ratio of the coefficients of the differenced regressions of mortality on the instruments to the endogenous regressor on the instruments. The changes in the payment rate are broken into five quintiles. As we might expect, higher increases in the payment rate change are correlated with higher increases in the total $\mathrm{M}+\mathrm{C}$ enrollment rate. ${ }^{21}$ The trend is most pronounced between the third and fourth quintiles of the payment increase. Breaking down the enrollment change into drug and non-drug enrollment, a movement from the fourth to the fifth quintile is associated with an increase in drug enrollment, but a decrease in non-drug enrollment. In other words, a moderate increase in the payment rate between 1993 and 2000 was linked with a general increase in managed care enrollment, but a large increase in the payment rate was linked specifically with an increase in drug coverage and not with non-drug coverage.

Turning to the elderly mortality rate, in the fourth payment quintile (the payment quintile associated with an increase in non-drug HMO enrollment) there is a large increase in elderly mortality rates. However, there is an equally large decrease in mortality in the fifth quintile of the

\footnotetext{
${ }^{20}$ The within-county standard deviation is $\$ 26.3$ prior to the passage of the BBA, and $\$ 15.2$ afterwards. The smaller number after the BBA enactment is consistent with the fact that innovations to the payments are largely divorced from shocks in the county after the enactment. The smaller size of both of these figures relative to the overall figure shows that the BBA substantially altered the payment scheme, and hence provides us with a useful source of variation.

${ }^{21}$ The quintiles for the changes in penetration rates do not sum to 3 , because they all have mass points at 0 , resulting from counties that had zero penetration in 1993 and 1998.
} 
payment rates which is the quintile associated with a large increase in drug $\mathrm{M}+\mathrm{C}$ enrollment. These results foreshadow our regression analysis findings and suggest that the relationship between mortality and $\mathrm{M}+\mathrm{C}$ enrollment will indeed be a function of the benefits offered by the $\mathrm{M}+\mathrm{C}$ plans.

\section{Results}

\section{Parameter estimates and implied magnitudes}

Table 4 presents the main results of the paper, estimates of equations (7) and (8). We present 7 specifications, which differ in the estimation methods, dependent variables and controls. Specification 1 provides an OLS regression of the log model (8) of the impacts of $\mathrm{M}+\mathrm{C}$ drug and non-drug coverages with only year dummies as controls, as a baseline comparison. In this and all other specifications, the omitted category is Medicare FFS. This specification shows that a higher $\mathrm{M}+\mathrm{C}$ non-drug coverage is associated with a lower elderly mortality rate than Medicare FFS within a year, although without a statistically significant difference, and that $\mathrm{M}+\mathrm{C}$ drug coverage is associated with a still lower elderly mortality rate, with a statistically significant difference from Medicare FFS. This regression is consistent with the idea that managed care and drug coverage both lower mortality, but also consistent with a number of other hypotheses based on selection.

Specification 2 adds in county and year fixed effects and the detailed demographic controls noted in the table. Unlike Specification 1, this specification shows that counties with an increase in managed care penetration had an increase in mortality. Consistent with Specification 1 , the increase in mortality is higher for counties with non-drug coverage than with drug coverage. While this specification does control for fixed effects, it does not directly use any credible source of exogenous variation in the managed care penetration rate or in drug coverage. 
Specification 3 provides our base specification, and uses the fixed effects IV model with the instruments and forward-mean-differencing procedure detailed in Section 3. We estimate the impact of $\mathrm{M}+\mathrm{C}$ drug coverage on elderly mortality to be very similar to Specification 2 . However, we estimate the impact of $\mathrm{M}+\mathrm{C}$ non-drug coverage to be much worse, with a coefficient that is almost 7 times as large as in Specification 2. Thus, our main finding is that $\mathrm{M}+\mathrm{C}$ plans without drug coverage are significantly worse than ones with drug coverage, but that $\mathrm{M}+\mathrm{C}$ plans with drug coverage have no significant mortality impact relative to Medicare FFS.

Using the coefficients from this specification, we find that moving $1 \%$ of Medicare enrollees, all with the mean mortality rate of $5.08 \%$, from an $\mathrm{M}+\mathrm{C}$ non-drug plan to an $\mathrm{M}+\mathrm{C}$ drug plan would reduce the elderly mortality rate by .014 percentage points. There are other plan attributes besides drug coverage which may be (positively or negatively) correlated with the drug benefit. These include the benefit offerings noted in Section 2 as well as the possibility of wider physician networks. We believe that these attributes are unlikely to have a mortality impact and hence that our estimated effect is due to drug coverage. ${ }^{22}$ This information in combination with the 34.3 million elderly Medicare enrollees in 2000 implies that the $1 \%$ move would save about 4,900 lives.

Evaluating the average economic value of $\mathrm{M}+\mathrm{C}$ drug coverage is somewhat difficult, because it depends on the expected number of years and quality of the remaining life for each person under consideration for receiving drug treatment. However, we can give some plausible bounds to this value. Conservatively, we assume that the mortality gains from drug coverage are limited to only one extra year of life, we value only mortality gains and we use $\$ 75,000$ as the net value of a life year (following Cutler and McClellan, 2001). This yields an average per-capita

\footnotetext{
${ }^{22}$ Importantly, very few $\mathrm{M}+\mathrm{C}$ non-drug enrollees had drug coverage, due to the fact that alternative drug coverages generally duplicate $\mathrm{M}+\mathrm{C}$ benefits. For instance, only $9 \%$ of $\mathrm{M}+\mathrm{C}$ non-drug enrollees had drug coverage in 2000 , according to the Medicare Current Beneficiary Survey.
} 
value of drug coverage of approximately $\$ 1,125$. An upper bound calculation can be made by assuming that a death avoided returns a person to the mean health status and life expectancy of her age cohort. Using data on mortality probabilities and life expectancy from life tables for 2000 from the National Center for Health Statistics (Arias, 2002) and the same net value of a life year yields an average per-capita value of approximately $\$ 10,200$. It is instructive to compare these values to the cost of drug coverage provision. The typical difference in the annual premiums between Medigap $\mathrm{G}$ and $\mathrm{J}$ plans (which are similar in benefits except that only $\mathrm{J}$ offers drug coverage) in 2000 is about $\$ 760 .^{23}$ Thus, even our conservative estimates suggest that drug coverage adds a substantial benefit over its cost.

Understanding the relative mortality impact of Medicare FFS and $\mathrm{M}+\mathrm{C}$ is more subtle. Due to data limitations, Medicare FFS enrollees with and without drug coverage are combined into one category. Davis et al. (1999) report that $63 \%$ of Medicare FFS enrollees had drug coverage in 1995. It is likely that Medicare FFS enrollees for whom drug coverage would lower the probability of mortality are more likely to obtain drug coverage than others, implying that $63 \%$ is a likely lower bound on FFS drug coverage for enrollees for whom drug coverage would lower mortality. The $\mathrm{M}+\mathrm{C}$ drug coefficient can be interpreted as capturing both the effect of moving a group to HMOs and of moving some fraction of the group, likely less than $37 \%$, to drug coverage. Thus, our coefficient estimates are consistent with the notion that HMOs have no overall mortality impact.

Specifications 4-7 provide different robustness checks of the findings in Specification 3. Specification 4 drops the $\log$ mortality rate of middle-aged individuals, age 50-59, as a regressor. This statistically significant control is potentially important because it will proxy for a variety of time-varying local attributes that can affect mortality and are potentially correlated

\footnotetext{
${ }^{23}$ Authors' calculation using AARP data from California.
} 
with the instruments, such as shifting unobserved local demographic patterns or time-varying local changes to practice style. We find that dropping this younger mortality rate results in estimated effects of $\mathrm{M}+\mathrm{C}$ drug and non-drug coverage that are virtually unchanged from Specification 3. The implication is that while the middle-aged mortality rate in a county is an important predictor for the elderly mortality rate, the above effects for which it proxies are not correlated with the instruments, both conditional on all the other regressors. We believe that the stability of the results across these specifications also provides further evidence against other potential non-included regressors influencing our main estimated coefficients.

Specification 5 uses the same controls and instruments as the base but with the linear model in (7) instead of the log model in (8). Although the coefficients are not directly comparable to those of the base because of the different dependent variable, we find the same relative impacts as in the base. In addition, the magnitudes are very similar, with the $1 \%$ move from $\mathrm{M}+\mathrm{C}$ non-drug to drug plans also reducing the elderly mortality rate by .014 percentage points. We prefer using the log specification because it allows for the proportional scaling of factors such as the middle-aged mortality rate.

Specification 6 reports results from the same specification as the base but using standard fixed effects IV instead of the forward mean differenced procedure. This procedure generates coefficients that imply a similar, but slightly higher mortality impact from both the $\mathrm{M}+\mathrm{C}$ drug and non-drug than in the base specification. This suggests that the bias from the short panel and instruments that are not strictly exogenous is small.

Specification 7 is similar to the base but adds in a state-level proxy for the $\log$ Plan $\mathrm{H}$ Medigap premium. We obtain results that are very similar to the base. The Medigap coefficient, which we do not report in the table, is small and insignificant, with a t statistic of -.54. This 
variable is likely not significant in part because it is a rough proxy of the availability of supplemental coverage and/or because there may be little demand elasticity to Medigap premiums among enrollees for whom drug coverage might affect mortality. We do not include the premium for our other specifications because of its lack of significance and the fact that the premium data are not available everywhere and hence would lower the sample size. We also estimated, but do not report, specifications with fewer instruments. These specifications also give similar results. $^{24}$

Table 5 provides evidence on the impact of $\mathrm{M}+\mathrm{C}$ drug and non-drug coverage on a number of different groups. All specifications use the FE IV forward-mean-differenced method to control for endogenous selection into plan type. The specifications follow the base with some small deviations in the controls, noted in the table.

Specifications 1 and 2 report the impact of $\mathrm{M}+\mathrm{C}$ drug and non-drug coverage on mortality for the 65-74 and 75+ age groups, respectively. We find results that are similar to the base specification, with some small differences. The $\mathrm{M}+\mathrm{C}$ drug coefficient for the $65-74$ group changes sign to negative but is still insignificant. The non-drug $\mathrm{M}+\mathrm{C}$ coefficients remain significant and large, though are slightly different in magnitudes than the base.

Specifications 3 and 4 estimate the impact of $\mathrm{M}+\mathrm{C}$ drug and non-drug coverage on disease-specific elderly mortality rates. We chose the two diseases with the largest mortality for the elderly, cancer and heart disease. We find that $\mathrm{M}+\mathrm{C}$ drug enrollment causes a significantly positive increase in the heart disease mortality rate, with $\mathrm{M}+\mathrm{C}$ non-drug enrollment causing an even larger impact, though not significant. These results suggest that managed care (as opposed to the lack of drug coverage) causes worse outcomes for cardiac care, consistent with evidence

24 These specifications are available in an appendix to the NBER Working Paper version of this paper, http://www.nber/org/papers/w10204. 
that managed care provides less intensive cardiac care (see Chernew, Gowrisankaran and Fendrick, 2002) and that intensive cardiac treatments have a beneficial mortality impact (see Cutler, 2004). The results for cancer are somewhat different, in that $\mathrm{M}+\mathrm{C}$ drug coverage causes a small and insignificant negative impact on mortality, while $\mathrm{M}+\mathrm{C}$ non-drug coverage has a positive but insignificant impact on mortality. During our sample period, it is unlikely that intensive cancer treatments had substantial mortality impacts. However, anti-nausea drugs, which may contribute to survivorship by increasing the tolerance for chemotherapy, are mostly not covered by Medicare FFS.

Specification 5 estimates the impact of $\mathrm{M}+\mathrm{C}$ coverage on the 50 to 59 year old mortality rate, in order to test whether there are spillovers from Medicare managed care enrollment into the non-Medicare population. We include the commercial managed care penetration rate for this regression, in order to control for the health care of this cohort. The coefficients on the $\mathrm{M}+\mathrm{C}$ penetration rates have the same sign as in Table 5 and are similar in magnitude to the base estimates, but are insignificant. Thus, it is unclear from these results whether there are spillovers from the Medicare managed care market to other forms of managed care.

\section{Specification tests}

The causal interpretation of our results above depends crucially on our assumption of exogenous instruments. Accordingly, we have performed a number of statistical tests of the validity and usefulness of our instruments, all using our base specification, Table 4 Specification 3.

First, we tested the power of our instruments, by performing first-stage regressions of the endogenous regressors $\mathrm{d}_{\mathrm{tc}}$ and $\mathrm{n}_{\mathrm{tc}}$ on the instruments and exogenous regressors, as suggested by Bound, Jaeger and Baker (1995). As in the base specification, our tests forward mean difference 
variables to allow for fixed effects. These tests show that the instruments are strong predictors. We can strongly reject the null hypothesis that the instruments do not enter in these regressions, with $F(38,464)=11.94, p=.00$ for $d_{t c}$ and $F(37,464)=2.33, p=.00$ for $n_{t c}$, using clustered residuals. The reason for this result is that the substantial within-county variation in the payment rates is driving $\mathrm{M}+\mathrm{C}$ enrollment and drug benefits. We also jointly estimated the same two equations with a multivariate regression, in order to test whether the coefficients apart from the fixed effects are the same across the two equations. The test strongly rejects the coefficients being the same with $F(99,3498)=12.87, p=.00$. This implies that the first-stage projections of $d_{t c}$ and $n_{t c}$ are significantly different from each other, which is necessary to jointly identify the effects of drug and non-drug managed care coverage.

Second, we provide evidence on the serial correlation of the residual health shocks $v_{t c}$, since our main identifying assumption is a lack of correlation between $v_{t-3, c}$ and $v_{t c}$. Although this assumption is not directly testable, we can obtain some evidence by examining the correlation of the residual from a reduced-form regression of the dependent variable $\log \left(\frac{m_{t c}}{1-m_{t c}}\right)$ on all exogenous variables, including the instruments and fixed effects. We estimate this reduced-form regression specifying a within-county $\mathrm{AR}(1)$ process for the residual, and find an estimated correlation of $\rho=.1478$, which implies that the estimated correlation after 3 years is $\rho^{3}=.0032$. This does not seem consistent with a sizeable, positive serial correlation between $v_{t-3, \mathrm{c}}$ and $v_{\mathrm{tc}}$.

Third, we tested for the endogeneity of $\mathrm{M}+\mathrm{C}$ drug and non-drug coverage, by performing a Wu (1973) - Hausman (1978) test of our base specification against a specification without instruments, as given in Table 4, Specification 2. We can reject the exogeneity of the $\mathrm{M}+\mathrm{C}$ 
coverage rates, with $\chi^{2}(2)=4.24, p=.01$.

Last, we performed the LM test of overidentifying restrictions created by the fact that we

have 39 instruments but only 2 endogenous regressors. ${ }^{25} \mathrm{We}$ fail to reject the assumption that the instruments are exogenous, with $\chi^{2}(37)=33.2, \mathrm{p}=.65$.

\section{Explanation of our findings}

A likely explanation for our finding is that $\mathrm{M}+\mathrm{C}$ drug coverage encourages the elderly to take life-extending prescription drugs by lowering the marginal cost of drugs. There is substantial support for this in the literature. Anecdotally, physicians report that financially constrained patients "extend" their prescriptions by taking their drugs less frequently than prescribed (Lagnado, 1999).

The literature provides data-driven supporting evidence for this explanation. In 1995, $86.6 \%$ of Medicare beneficiaries had a prescription filled (Adams et al., 2001). Several studies (Lillard, Rogowski and Kington (1999), Davis et al. (1999) and Stuart and Grana (1998)) find a positive correlation between prescription insurance coverage and prescription drug usage in the elderly population. Poisal and Murray (2001) estimate that Medicare enrollees without drug coverage fill 2.4 fewer prescriptions than enrollees with drug coverage. Poisal and Chulis (2000) find that among Medicare enrollees with 3 or more limitations to the activities of daily living (ADLs), those without drug coverage use $43 \%$ less prescription drugs in dollar terms than the same population with prescription drug coverage. Using data from employer-based health coverage, Goldman et al. (2004) finds that increased out-of-pocket expenditures reduced the use of drugs for a variety of conditions.

None of these studies attempts to control for unobserved selection into drug coverage or

\footnotetext{
${ }^{25}$ See Hansen (1982).
} 
managed care. While these studies generally examine relatively small samples, without enough power to identify mortality differences, some recent studies (Lucarelli, 2006 and Yang, Gilleskie, and Norton, 2004) find that increased drug coverage reduces mortality among the elderly.

It is also useful to compare our estimated magnitude of 4,900 lives from the $1 \%$ movement to drug coverage to the literature. We perform "back-of-the-envelope" calculations for three common conditions for which data were available, high cholesterol, hypertension and diabetes, using the following formula: $\Delta$ mortality $=$ base mortality rate $\times(\%$ increase in mortality from condition) $\times$ prevalence of condition in Medicare population $\times \%$ reduction in mortality from prescription drug use $\times \%$ reduction in prescription drug use from lack of insurance $\times 1 \% \times$ size of Medicare population. We use a conservative base mortality rate of 3.5\%. Adams et al. (2001) report that the absence of drug coverage reduces the use of hypertension drugs for individuals with high blood pressure by $23 \%$. We use this estimate for all three conditions, as it appears to be roughly the median estimate from the sparse literature on compliance.

Our estimates indicate a large impact of drug coverage among patients with high cholesterol. This condition is prevalent $-50 \%$ of the elderly population has blood serum cholesterol levels in excess of $240 \mathrm{mg} / \mathrm{dL}$ (National Health and Nutrition Examination Survey III). Pekkanen et al. (1990) reports that serum blood cholesterol in excess of $240 \mathrm{mg} / \mathrm{dL}$ increases mortality risk by $350 \%$ for the elderly while Shepherd et al. (1995) find that pharmaceutical treatment for high blood cholesterol reduces all-cause mortality by $22 \%$. Combining the estimates yields a savings of 700 lives from drug coverage for high cholesterol enrollees. Performing similar calculations for hypertension and diabetes yield mortality increases 
of 240 and 330 lives, respectively. ${ }^{26}$ Since our "back-of-the-envelope" calculations of three common conditions result in an expected increase of approximately 1,260 lives, this suggests that our estimated value of 4,900 lives is plausible.

\section{Adverse selection and equilibrium provision of quality}

Our model implies the possibility of consumer selection into managed care plans based on their attributes. Our results from Table 4 suggest that there is in fact substantial adverse selection. In particular, a comparison of Specifications 1 and 3 shows that even though mortality rates for $\mathrm{M}+\mathrm{C}$ plans are substantially lower than for Medicare FFS, the causal effect of these plans is not to lower mortality rates. This shows that managed care plans are attracting a selection of patients who are less likely to die than the average Medicare FFS enrollee. ${ }^{27}$

Comparing Specifications 2 and 3, we see that a substantial portion of the relative selection into non-drug plans is based on the unobserved severity of illness, $v_{\mathrm{tc}}$. In particular, an examination of the coefficients suggests that non-drug $\mathrm{M}+\mathrm{C}$ enrollees are in significantly better health than drug $\mathrm{M}+\mathrm{C}$ enrollees, and that this adverse selection is based on different levels of the unobserved severity of illness, $v_{\mathrm{tc}}$. We verified this pattern by performing simple regressions using fitted values of $v_{t c}$ from the base specification. A regression of $d_{t c}$ on $v_{t c}$ and year dummies yielded a positive coefficient on $v_{\mathrm{tc}}$ with a t-statistic of 5.13, while a similar regression of $n_{t c}$ on $v_{t c}$ yielded a negative coefficient with a t-statistic of -5.36 .

Recall that our model has two potential sources of selection, enrollees and HMOs. The signs of the correlations noted above suggest that enrollees with high unobserved illness severity are disproportionately selecting drug plans, which is the demand response that we might expect.

\footnotetext{
${ }^{26}$ The inputs into the mortality formula for hypertension and diabetes are available from the authors upon request.

${ }^{27}$ Consistent with this, Town and Liu (2003) show that M+C enrollees have lower medical costs than Medicare FFS enrollees.
} 
Any HMO response to unobserved illness severity is likely to be the opposite, as there is likely a complementarity between illness severity and the cost of prescription drug treatment. Thus, the results imply that any HMO response to unobserved illness severity is dominated by the consumer response. This is consistent with the fact that information about enrollee health shocks may take longer to filter to firms than to the enrollees themselves and the fact that HMOs must make decisions annually, while enrollees can make decisions monthly. Note that managed care plans attract people with low observed illness severity, consistent with HMO selection, but possibly also with enrollee selection.

Although adverse selection was present in the market for $\mathrm{M}+\mathrm{C}$ drug plans, it did not cause this market to collapse. For instance, $71 \%$ of $\mathrm{M}+\mathrm{C}$ enrollees were enrolled in drug plans, a figure that was increasing over time. Moreover, in 2000, $87 \%$ of $\mathrm{M}+\mathrm{C}$ enrollees in plans without drug coverage had at least one plan with drug coverage in their county. This contrasts with other situations where plans with generous benefits have gone into a death spiral and collapsed after the payer implemented a payment scheme where the generous plans were reimbursed at the same rate as the less generous plans, similar to $\mathrm{M}+\mathrm{C}$ (see Cutler and Reber, 1998). The likely reasons why the $\mathrm{M}+\mathrm{C}$ drug market did not collapse includes the facts that the majority of plans capped the drug benefit to limit the adverse selection, that $\mathrm{M}+\mathrm{C}$ plans attracted healthy elderly people on average (which compensated for the fact that drug plans attracted less healthy people than nondrug plans), and that in many counties the government reimbursement during our sample period was generous thereby overcoming incentives induced by adverse selection.

In spite of the fact that the $\mathrm{M}+\mathrm{C}$ market did not collapse, our results suggest that its equilibrium outcomes may not be optimal. Specifically, since we find that there are significant net benefits associated with HMOs offering drug coverage, in the presence of adverse selection 
and insufficient reimbursement the number of plans offering that benefit is likely to be less than is optimal. There is some evidence that this is occurring in the Medicare HMO market. Among counties/years in our sample with an HMO present, $23.6 \%$ had no HMO that offered drug coverage. In addition, the literature has found that non-drug $\mathrm{M}+\mathrm{C}$ plans offer more benefits than drug plans, and that these non-drug benefits are valued by enrollees. ${ }^{28}$ Given that these non-drug benefits and drug benefits are very unlikely to be substitutes, this suggests that the market may sometimes underprovide attributes besides drug coverage. Last, though we did not model this, information problems may also cause further market failures. For instance, in $2000,40 \%$ of nondrug $\mathrm{M}+\mathrm{C}$ enrollees were enrolled in a plan that once offered drug coverage, suggesting the possibility that some enrollees without drug coverage did not know that their drug coverage had been dropped.

\section{Conclusions}

This study examines the impact the Medicare HMO program and drug coverage on the elderly mortality rate using a fixed effects IV estimator that is consistent with endogenous selection into managed care plans and drug coverage. We find that enrollment in an HMO that does not provide drug benefits significantly increases mortality while enrollment in an HMO offering drug coverage has no significant impact relative to Medicare FFS coverage. This finding is robust across a variety of IV specifications and holds for different age groups of the elderly. The magnitudes of our findings are large, but also consistent with the literature. Our findings suggest that the benefits of drug coverage are much higher than the costs.

The likely explanation for our results is that drug benefits causes Medicare enrollees to use more drugs which extends their lives. While we do not have evidence on the potential impact

\footnotetext{
${ }^{28}$ Consistent with this explanation, McBride (1998) finds an inverted U-shape relationship between the payment rate and the provision of $\mathrm{M}+\mathrm{C}$ non-drug benefits while Town and Liu (2003) find an inverse correlation between the value of the $\mathrm{M}+\mathrm{C}$ non-drug benefit offered by the plan and the likelihood they offer drug benefits.
} 
of drug coverage for Medicare FFS patients, we believe it will be similar since the methods of service provision are similar across the two types of plans. Apart from their role in the provision of drug benefits, HMOs appear to have little effect on mortality, although there is weak evidence that their cancer treatment quality may be better than Medicare FFS but that their heart disease treatment quality may be worse than Medicare FFS.

Our results suggest several policy implications. Most directly, they imply that policies to extend drug coverage to the elderly would be beneficial. In addition, they imply that moving Medicare enrollees towards managed care plans is not likely to have any adverse mortality consequences. The passage of the 2003 MMA is evidence that Congress made similar assessments, although the specifics of the MMA Part D drug coverage are significantly different from the typical $\mathrm{M}+\mathrm{C}$ drug coverage that we evaluate. Our results also imply that there are substantial selection differences between Medicare HMOs and Medicare FFS, and in particular, that $\mathrm{M}+\mathrm{C}$ non-drug plans tend to attract enrollees with a higher unobserved health status than average. The unobserved nature of the selection also suggests that any attempts by the Medicare administration to better adjust payments for observed patient risk status may not completely eliminate the adverse selection. However, reimbursement schemes that paid plans more to provide drug benefits to enrollees would alleviate this selection problem, and potentially help the market function more efficiently. 


\section{References}

Adams, A., Soumerai, S., and Ross-Degnan, D. (2001). "Use of antihypertensive drugs by Medicare enrollees: Does type of drug coverage matter?" Health Affairs 20(1): 276-286.

Arellano, M. and Bond, S. (1991). "Some tests of specification for panel data: Monte Carlo evidence and an application to employment equations," Review of Economic Studies 58: 277-297.

Arias, E. (2002). United States Life Tables, 2000, National Vital Statistics Reports 1(2), Hyattsville, MD: National Center for Health Statistics.

Baker, L.C. and Brown, M.L. (1999). "Managed care, consolidation among health care providers, and health care: evidence from mammography," RAND Journal of Economics 30(2): 351-374.

Berry, S. (1994). "Estimating discrete-choice models of product differentiation," RAND Journal of Economics 25(2): 242-62.

Bound, J., Jaeger, D.A., and Baker, R. (1995). "Problems with instrumental variables estimation when the correlation between the instruments and the endogenous explanatory variables is weak," Journal of the American Statistical Association 90: 443-50.

Chernew, M., Gowrisankaran, G., and Fendrick, A.M. (2002). "Payer type and the returns to bypass surgery: evidence from hospital entry behavior," Journal of Health Economics 21: 451-474.

Cutler, David M. (2004). Your Money or Your Life. New York: Oxford University Press.

Cutler, David M. and McClellan, Mark (2001). "Is technological change in medicine worth it?" Health Affairs 20: 11-29. 
Cutler, David M., McClellan, Mark, and Newhouse, Joseph P. (2000). "How does managed care do it?" RAND Journal of Economics 31: 526-48.

Cutler, David M. and Reber, Sarah J. (1998). "Paying for health insurance: the trade-off between competition and adverse selection," Quarterly Journal of Economics 113(2): 438-66.

Davis, M., Poisal, J., Chulis, G., Zarabozo, C., and Cooper, B. (1999). "Prescription drug coverage, utilization, and spending among Medicare beneficiaries," Health Affairs 18(2): 231-243.

Donabedian, A. (1985). The Methods and Findings of Quality Assessment and Monitoring: An Illustrated Analysis, Vol. 3. Ann Arbor, MI: Health Administration Press.

Dranove, D., Simon, C., and White, W. (2002). "Is managed care leading to consolidation in healthcare markets?" Health Services Research 27(3): 573-94.

Eggers, P.W., Frankenfield, D.L., Greer, J.W., McClellan, W., Owen, W.F. Jr., and Rocco, M.V. (2002). "Comparison of mortality and intermediate outcomes between Medicare dialysis patients in HMO and fee for service," American Journal of Kidney Disorders 39(4): 796804.

Glied, S. (2000). "Managed care," in Handbook of Health Economics. Cuyler, A. and Newhouse, J., ed., Amsterdam: Elsevier Science.

Goldman, D.P., Joyce, G.F., Escarce, J.J., Pace, J.E., Solomon, M.D., Laouri, M., Landsman, P.B., and Teutsch, S.M. (2004). "Pharmacy benefits and the use of drugs by the chronically ill," Journal of the American Medical Association 291 (19): 2344-2350.

Hansen, L. (1982). "Large sample properties of generalized method of moments estimators," Econometrica 50: 1029-54.

Hausman, J. (1978). "Specification tests in econometrics," Econometrica 46: 1251-71. 
Keane, M.P. and Runkle, D.E. (1992). "On the estimation of panel-data models with serial correlation when instruments are not strictly exogenous," Journal of Business and Economic Statistics 10: 1-9.

Keeler, E., Brook, R.H., Goldberg, G.A., Kamberg, C. J., and Newhouse, J.P. (1985). "How free care reduced hypertension in the health insurance experiment," Journal of the American Medical Association 254: 1926 - 1931.

Lagnado, L. (1999). "Drug costs can leave elderly a grim choice: pills or other needs," Wall Street Journal Nov. 11: A1.

Lee-Feldstein, A., Feldstein, P., Buchmueller, T., and Katterhagen, G. (2000). "The relationship of HMOs, health insurance, and delivery systems to breast cancer outcomes," Medical Care 38(7):705-718.

Lichtenberg, F. (2002a). "Sources of U.S. longevity increase, 1960 - 1997." Cambridge, MA: NBER Working Paper 8755.

Lichtenberg, F. (2002b). "The effect of changes in drug utilization on labor supply and per-capita output.” Cambridge, MA: NBER Working Paper 9139.

Lillard, L., Rogowski, J., and Kington, R. (1999). "Insurance coverage for prescription drugs: effects on use and expenditures in the Medicare population," Medical Care 37(9): 926936.

Lucarelli, C. (2006). "An analysis of the Medicare prescription drug benefit." Mimeo, Cornell University.

Maciejewski, M. L., Dowd, B., Call, K., and Feldman, R. (2001). “Comparing mortality and time until death for Medicare HMO and FFS beneficiaries," Health Services Research 35(6): $1245-1265$. 
McAdams, D. and Schwarz, M. (2006). "Perverse incentives in the Medicare prescription drug benefit.” Cambridge, MA: NBER Working Paper 12008.

McBride, T. (1998). "Disparities in access to Medicare managed care plans and their benefits," Health Affairs 17(6): 170-180.

Miller, R.H. and Luft, H.S. (2002). "HMO plan performance update: an analysis of the literature, 1997-2001," Health Affairs 21(4): 63-86.

Pekkanen, J., Linn, S., Heiss, G., Suchindran, C.M., Leon, A., Rifkind, B.M., and Tyroler, H.A. (1990). "Ten-year mortality from cardiovascular disease in relation to cholesterol level among men with and without preexisting cardiovascular disease," New England Journal of Medicine 322(24): 1700-1707.

Poisal, J. and Chulis, G. (2000). "Medicare beneficiaries and drug coverage," Health Affairs 19(2): $248-256$.

Poisal, J. and Murray, L. (2001). “Growing differences between Medicare beneficiaries with and without drug coverage," Health Affairs 20(2): 74-85.

Potosky, A.L., Merrill, R.M., Riley, G.F., Taplin, S.H., Barlow, W., Fireman, B.H., and Lubitz, J.D. (1999). "Prostate cancer treatment and ten year survival among group/staff HMO and fee-for-service Medicare patients," Health Services Research 34(2): 525-46.

Roetzheim, R.G., Gonzalez, E.C., Ferrante, J.M., Pal, N., Van Durme, D.J., and Krischer, J.P. (2000). "Effects of health insurance and race on breast carcinoma treatments and outcomes," Cancer 89(11): 2202-2213.

Riley, G., Lubitz, J., and Rabey, E. (1991). "Enrollee health status under Medicare risk contracts: An analysis of mortality rates," Health Services Research 26(2): 137-163.

Riley, G., Rabey, E., and Kasper, J. (1989). "Biased selection and regression toward the mean in 
three Medicare HMO demonstrations: A survival analysis of enrollees and disenrollees," Medical Care 27(4): 337-347.

Sada, M.J., French, W.J., Carlisle, D.M., Chandra, N.C., Gore, J.M., and Rogers, W.J. (1998). "Influence of payor on use of invasive cardiac procedures and patient outcome after myocardial infarction the United States," Journal of the American College of Cardiology 31(7): 1474-1480.

Shepherd, J., Cobbe, S.M., Ford, I., Isles, C.G., Lorimer, A.R., MacFarlane, P.W., McKillop, J.H., and Packard, C.J. (1995). "Prevention of coronary heart disease with pravastatin in men with hypercholesterolemia," New England Journal of Medicine 333(20): 1301-1307.

Stuart, B. and Grana, J. (1998). "Ability to pay and the decision to medicate," Medical Care 36(2): 202-211.

Town, R.J. and Liu, S. (2003). "The welfare impact of Medicare HMOs," Rand Journal of Economics 34: 719-736.

$\mathrm{Wu}, \mathrm{D}$. (1973). "Alternative tests of independence between stochastic regressors and disturbances," Econometrica 41: 733-50.

Yang, Z, Gilleskie, D., and Norton, E. (2004). "Prescription drugs, medical care, and health outcomes: a model of elderly health dynamics." Cambridge, MA: NBER Working Paper 10964. 


\section{Table 1:}

Mortality Data Table

Data Set

Source

Variables

Multiple Cause of Death Data

State-County-Plan Penetration file and $\mathrm{M}+\mathrm{C} / \mathrm{AAPCC}$

Standardized Per Capita Rates of Payment

Medicaid Program Statistics

Area Resource File

Population Estimates Program

InterStudy

Medigap Premium
National Center for Health Statistics - National

Vitality Statistics

Center for Medicare and Medicaid Services

Center for Medicare and Medicaid Services

Area Resource File

Bureau of the Census

InterStudy

AARP
Mortality rates by age and cause of death

$\mathrm{M}+\mathrm{C}$ enrollments by $\mathrm{HMO}$ benefit structure and CMS payment data

Medicaid enrollments by age classification

Population by race, poverty rates, per-capita income, number of MDs and hospitals.

Predicted population by age and sex categories Commercial HMO
enrollment

Medigap Premiums for Plan $\mathrm{H}$ 


\section{Table 2:}

Summary statistics by county and year

Variable

Mortality rate, age $65+$

(\%)

Mortality rate, age 65-74

(\%)

Mortality rate, age $75+$

$$
(\%)
$$

Mortality rate, age 50-59

(\%)

Heart disease mortality

rate, age $65+(\%)$

Cancer mortality rate, age

$$
65+(\%)
$$

MDs per capita (thousands)

Hosp. beds per capita (thousands)

Percent elderly

Income (thousands)

Unemployment rate

$$
\text { (\%) }
$$

Total population (thousands)

$\mathrm{M}+\mathrm{C}$ drug penetration rate (\%)

$\mathrm{M}+\mathrm{C}$ drug penetration rate $=0(\%)$

$\mathrm{M}+\mathrm{C}$ non-drug penetration rate $(\%)$

$\mathrm{M}+\mathrm{C}$ non-drug penetration rate $=0(\%)$

$\mathrm{M}+\mathrm{C}$ monthly payment rate $(2000 \$)$

$\mathrm{N}$
Entire sample

$5.08(.52)$

$2.54(.38)$

$8.26(.76)$

$.54(.13)$

$1.73(.28)$

$1.00(.18)$

$2.5(1.8)$

$3.4(2.1)$

$12.5(3.9)$

$\$ 25.2(6.7)$

$5.0(2.7)$

$422(626)$

$7.2(12.0)$

$49.0(50.0)$

$3.7(7.8)$

$59.8(49.0)$

$\$ 445(\$ 84)$

3,612
1993

2000

$5.17(.46)$

$5.04(.56)$

$2.64(.36)$

$2.41(.39)$

$8.16(.73)$

$.51(.13)$

$1.64(.27)$

$1.11(.12)$

$2.6(1.8)$

$3.0(1.9)$

$12.5(3.8)$

$12.4(3.6)$

$\$ 20.9(\$ 4.5)$

$\$ 29.7(\$ 7.8)$

$3.9(2.4)$

$6.5(2.2)$

455 (766)

$442(654)$

$1.4(5.1)$

11.9 (14.9)

$34.6(47.6)$

$3.9(8.5)$

$1.9(5.1)$

$65.5(47.5)$

$68.1(46.7)$

$\$ 398$ (\$70)

$\$ 497(\$ 72)$

409

Note: each cell provides the mean value with the standard deviation in parentheses. 


\section{Table 3:}

Changes in payment rate, mortality, and

$\mathrm{M}+\mathrm{C}$ enrollment, 1993-2000

$\begin{array}{ccccc}\begin{array}{c}\text { Quintile and range of } \\ \text { change in payment } \\ \text { rate: }\end{array} & \begin{array}{c}\text { Percentage } \\ \text { point change in } \\ \text { total } \mathrm{M}+\mathrm{C} \\ \text { enrollment }\end{array} & \begin{array}{c}\text { Percentage } \\ \text { point change in } \\ \mathrm{M}+\mathrm{C} \text { non-drug } \\ \text { enrollment }\end{array} & \begin{array}{c}\text { Percentage } \\ \text { point change in } \\ \mathrm{M}+\mathrm{C} \text { drug } \\ \text { enrollment }\end{array} & \begin{array}{c}\text { Percentage } \\ \text { point change in } \\ \text { elderly } \\ \text { mortality }\end{array} \\ \begin{array}{c}{[\$ 40-\$ 80]} \\ 2\end{array} & -1.3 & -.89 & -.40 & .016 \\ {[\$ 81-\$ 95]} & -.16 & .11 & -.26 & .019 \\ 3 & & & & \\ {[\$ 96-\$ 107]} & -.47 & .0075 & -.47 & -.030 \\ 4 & & & & .050 \\ {[\$ 108-\$ 124]} & .20 & 1.1 & -.93 & \\ 5 & 1.8 & & & -.055\end{array}$

Note: Each cell provides the mean percentage point change of the given variable when the change in the $\mathrm{M}+\mathrm{C}$ payment rate is in the specified quintile, after subtracting the overall mean change percentage point from 1993 to 2000. 


\section{Table 4:}

Elderly mortality rate on $\mathrm{M}+\mathrm{C}$ penetration rates

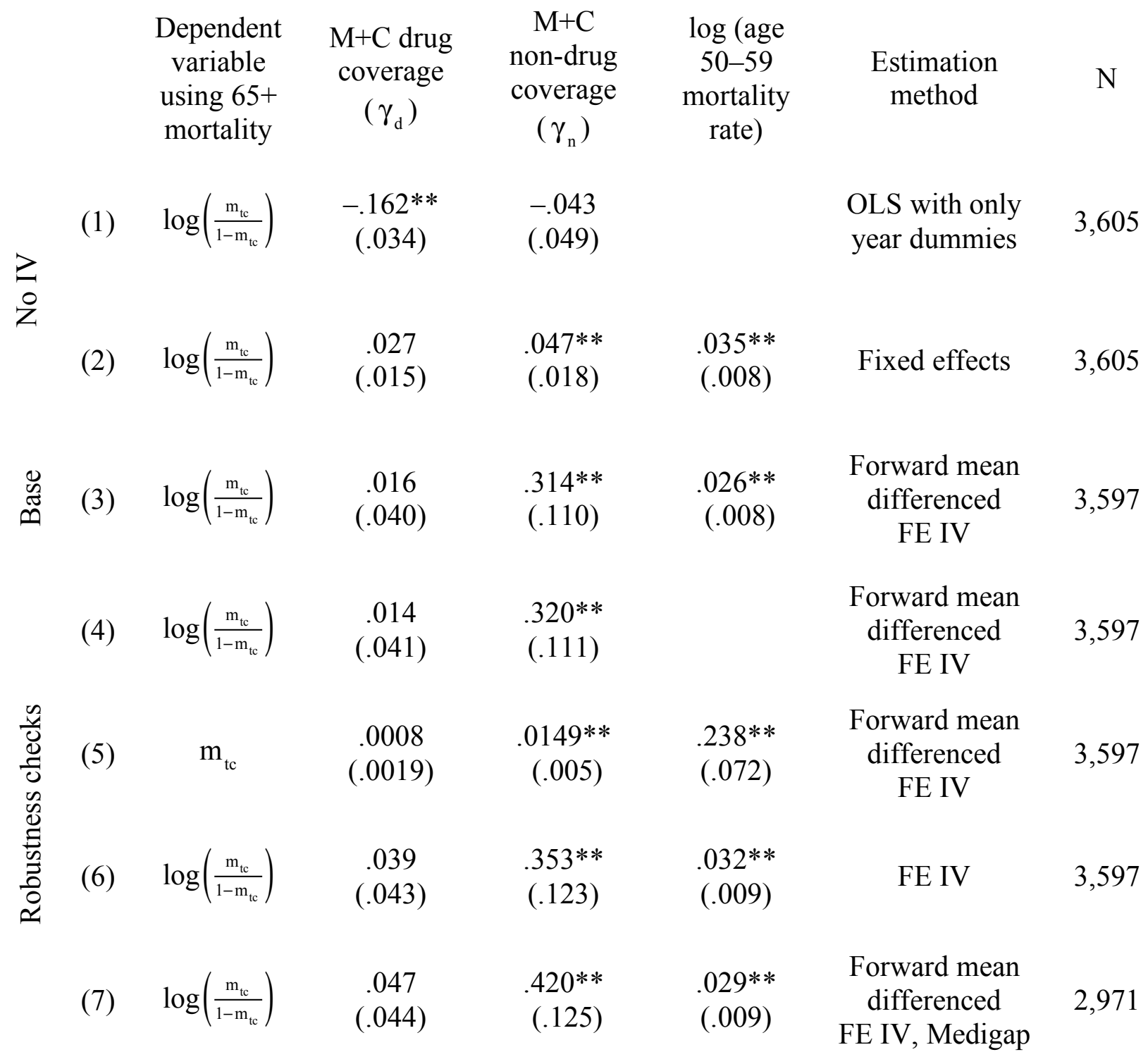

Note: All specifications include year fixed effects. Specifications 2 through 6 include the following controls: percent elderly in Medicaid, percent of population 65 and over, percent of population in poverty, log per capita income, unemployment rate, MDs and hospital beds per capita, percent white, black and Hispanic, five regional time trends, the percent of elderly at each age/sex cell and county fixed effects. Specification 7 includes these controls and the log of the Medigap Plan H premium. All standard error calculations are clustered at the county level. The instrument set is as specified in Section 3.

** Significant at the $1 \%$ level

* Significant at the $5 \%$ level 


\section{Table 5:}

Mortality rates for different groups on $\mathrm{M}+\mathrm{C}$ penetration rates

\begin{tabular}{|c|c|c|c|c|}
\hline $\begin{array}{l}\text { Dependent variable } \\
\text { using } \log \left(\frac{\mathrm{m}_{\mathrm{tc}}}{1-\mathrm{m}_{\mathrm{tc}}}\right)\end{array}$ & $\begin{array}{c}\mathrm{M}+\mathrm{C} \text { drug } \\
\text { coverage }\left(\gamma_{\mathrm{d}}\right)\end{array}$ & $\begin{array}{c}\mathrm{M}+\mathrm{C} \\
\text { non-drug } \\
\text { coverage }\left(\gamma_{\mathrm{n}}\right)\end{array}$ & $\begin{array}{l}\log (\text { age } 50-59 \\
\text { mortality rate) }\end{array}$ & $\mathrm{N}$ \\
\hline $\begin{array}{c}\text { Mortality rate } \\
\text { age } 75+\end{array}$ & $\begin{array}{l}.038 \\
(.049)\end{array}$ & $\begin{array}{l}.277^{*} \\
(.129)\end{array}$ & $\begin{array}{l}.030 * * \\
(.010)\end{array}$ & 3,597 \\
\hline $\begin{array}{l}\text { Mortality rate } \\
\text { age } 65-74\end{array}$ & $\begin{array}{l}-.040 \\
(.056)\end{array}$ & $\begin{array}{l}.370 * * \\
(.146)\end{array}$ & $\begin{array}{l}.022 * * \\
(.014)\end{array}$ & 3,597 \\
\hline $\begin{array}{c}\text { Heart disease } \\
\text { mortality rate } 65+\end{array}$ & $\begin{array}{l}.167 * \\
(.071)\end{array}$ & $\begin{array}{l}.311 \\
(.171)\end{array}$ & $\begin{array}{l}.004 \\
(.015)\end{array}$ & 3,597 \\
\hline $\begin{array}{c}\text { Cancer mortality } \\
\text { rate } 65+\end{array}$ & $\begin{array}{l}-.118 \\
(.064)\end{array}$ & $\begin{array}{l}.179 \\
(.173)\end{array}$ & $\begin{array}{l}.035^{* *} \\
(.019)\end{array}$ & 3,597 \\
\hline $\begin{array}{c}\text { Mortality rate } \\
\text { age } 50-59\end{array}$ & $\begin{array}{l}-.028 \\
(.089)\end{array}$ & $\begin{array}{l}.223 \\
(.258)\end{array}$ & & 3,479 \\
\hline
\end{tabular}

Note: All estimation is performed using the forward-mean-differenced FE IV estimator. All specifications include the following controls: percent population in Medicaid for age range, percent of population 65 and over, percent of population in poverty, log per capita income, unemployment rate, MDs and hospital beds per capita, percent white, black and Hispanic, five regional time trends, the percent of elderly at each age/sex cell and year and county fixed effects. Specifications 3 and 4 include the heart disease and cancer mortality rates for age 50-59, respectively. Specification 5 includes the commercial HMO penetration rate. All standard error calculations are clustered at the county level. The instrument set is as specified in Section 3.

** Significant at the $1 \%$ level

* Significant at the 5\% level 


\title{
Appendix Table 1:
}

Estimation using alternate instrument sets

Instruments

\begin{tabular}{|c|c|c|}
\hline $\begin{array}{c}\mathrm{M}+\mathrm{C} \text { drug } \\
\text { coverage }\left(\gamma_{\mathrm{d}}\right)\end{array}$ & $\begin{array}{c}\mathrm{M}+\mathrm{C} \\
\text { non-drug } \\
\text { coverage }\left(\gamma_{n}\right)\end{array}$ & $\begin{array}{l}\log (\text { age } 50-59 \\
\text { mortality rate) }\end{array}$ \\
\hline
\end{tabular}

39 instruments:

(1) see base specification in paper

\author{
.016 \\ (.040)
}

$.314 * *$

$.026^{* *}$

(.110)

(.008)

3,597

13 instruments:

(2)

$\begin{array}{cccc}\text { current-year } & .009 & .202 & .027 * * \\ \begin{array}{c}\text { instruments from the } \\ \text { base specification }\end{array} & (.040) & (.126) & (.008)\end{array}$

$-.0155$

$.323 *$

$.026^{* *}$

(.042)

(.163)

(.008)

3,597

$$
\log \hat{\mathrm{r}}_{\mathrm{tc}}
$$

10 instruments:

(4)

same as (2) except

without neighboring

county information

$$
.008
$$

.216

(.129)

$.030 * *$

(.0079)

3,605

8 instruments: same as

(5)

(4) except without $\log$

$\hat{\mathrm{r}}_{\mathrm{tc}}$ or its square

$-.0028$

$.323^{*}$

$(.138)$

$.026 * *$

$(.008)$

3,605

Note: All estimation is performed using the forward-mean-differenced FE IV estimator. Dependent variable is $\log \left(\frac{\mathrm{m}_{\mathrm{tc}}}{1-\mathrm{m}_{\mathrm{tc}}}\right)$ using $65+$ mortality. Specifications include the following controls: percent elderly in Medicaid, percent of population 65 and over, percent of population in poverty, log per capita income, unemployment rate, MDs and hospital beds per capita, percent white, black and Hispanic, five regional time trends, the percent of elderly at each age/sex cell and year and county fixed effects. All standard error calculations are clustered at the county level. Specification 1 is the base specification, also in Table 4, Specification 3.

** Significant at the $1 \%$ level

* Significant at the 5\% level 